\title{
Synthesis and Characterization of Metal Hydride/Carbon Aerogel Composites for Hydrogen Storage
}

\author{
Kuen-Song Lin, ${ }^{1}$ Yao-Jen Mai, ${ }^{1}$ Su-Wei Chiu, ${ }^{1}$ Jing-How Yang, ${ }^{1}$ and Sammy L. I. Chan ${ }^{2}$ \\ ${ }^{1}$ Department of Chemical Engineering and Materials Science, Fuel Cell Center, Yuan Ze University, Chungli 320, Taiwan \\ ${ }^{2}$ School of Materials Science and Engineering, The University of New South Wales, Sydney, NSW 2052, Australia \\ Correspondence should be addressed to Kuen-Song Lin, kslin@saturn.yzu.edu.tw
}

Received 21 June 2012; Accepted 15 August 2012

Academic Editor: Hamed Bahmanpour

Copyright ( $) 2012$ Kuen-Song Lin et al. This is an open access article distributed under the Creative Commons Attribution License, which permits unrestricted use, distribution, and reproduction in any medium, provided the original work is properly cited.

\begin{abstract}
Two materials currently of interest for onboard lightweight hydrogen storage applications are sodium aluminum hydride $\left(\mathrm{NaAlH}_{4}\right)$, a complex metal hydride, and carbon aerogels (CAs), a light porous material connected by several spherical nanoparticles. The objectives of the present work have been to investigate the synthesis, characterization, and hydrogenation behavior of Pd-, Ti- or Fe-doped CAs, $\mathrm{NaAlH}_{4}$, and $\mathrm{MgH}_{2}$ nanocomposites. The diameters of Pd nanoparticles onto CA's surface and BET surface area of CAs were 3-10 $\mathrm{nm}$ and $700-900 \mathrm{~m}^{2} \mathrm{~g}^{-1}$, respectively. The $\mathrm{H}_{2}$ storage capacity of metal hydrides has been studied using high-pressure TGA microbalance and they were 4.0, 2.7, 2.1, and $1.2 \mathrm{wt} \%$ for $\mathrm{MgH}_{2}-\mathrm{FeTi}-\mathrm{CAs}, \mathrm{MgH}_{2}-\mathrm{FeTi}, \mathrm{CAs}-\mathrm{Pd}$, and $8 \mathrm{~mol} \%$ Ti-doped $\mathrm{NaAlH}_{4}$, respectively, at room temperature. Carbon aerogels with higher surface area and mesoporous structures facilitated hydrogen diffusion and adsorption, which accounted for its extraordinary hydrogen storage phenomenon. The hydrogen adsorption abilities of CAs notably increased after inclusion of metal hydrides by the "hydrogen spillover" mechanisms.
\end{abstract}

\section{Introduction}

Hydrogen is recognized as a clean fuel because of its almost complete combustion in air with notably high energy delivery ability. Recently, owning to the need for efficient and safe $\mathrm{H}_{2}$ storage, enormous attention has been paid on the advantages of synthesizing composite metal hydrides [1-3]. Complex metal hydride composites in the form of $\mathrm{ABH}_{4}$, where $\mathrm{A}$ is an alkali metal and $\mathrm{B}$ is a group III element, have been widely studied in solution as proton acceptors to enhance $\mathrm{H}_{2}$ adsorption abilities [4-7]. $\mathrm{NaAlH}_{4}$ is different from any other metal hydrides and borohydrides with similar structures since it is capable to reversibly store $\mathrm{H}_{2}$ after doping with transition metals (e.g., Ti, Fe, or $\mathrm{Zr}$ ) [8-10]. Ti-doping also improves significantly the kinetic and cycling performance of $\mathrm{NaAlH}_{4}$ at moderate temperatures around $373 \mathrm{~K}$ and ambient pressures. All these properties make it suitable as mobile, lightweight $\mathrm{H}_{2}$ storage materials for potential application on a hydrogen fuel cell [11-23]. Practically, achievable $\mathrm{H}_{2}$ storage capacity for $\mathrm{Ti}^{-} \mathrm{NaAlH}_{4}$ is only $3.7 \mathrm{wt} \%$, falls short of the theoretical value of $5.6 \mathrm{wt} \%$ for $\mathrm{NaAlH}_{4}$ [20-23].
Magnesium and its alloys are potential hydrogen storage material because of their very high hydrogen storage abilities. $\mathrm{MgH}_{2}$ is also relatively light and cheaper when compared with other metal hydrides. Magnesium is often alloyed with transition metals (e.g., $\mathrm{Fe}, \mathrm{Ti}, \mathrm{Zr}, \mathrm{Zn}$, or $\mathrm{Mn}$ ) to increase the adsorption and desorption rates [24-29]. Similarly, FeTi is a viable compound with a hydrogen adsorption capacity of around $1.90 \mathrm{wt} \%$. However, activation process of $\mathrm{FeTi}$ is necessary to get rid of the $\mathrm{TiO}_{2}$ layer, which would otherwise hinder the hydrogenation/dehydrogenation. Consequently, higher temperatures and pressures are frequently required to achieve reproducible, maximum hydrogen adsorption/desorption capacities in the compounds [30].

Palladium-doped monolithic carbon aerogels (CAs) show a high surface area and pore volume. These characteristics are strongly influenced by the chemical nature, distribution and dispersion of the palladium particles [3133]. Furthermore, addition of $1 \mathrm{wt} \% \mathrm{Pd}$ can be effective for the hydrogen adsorption capacity of FeTi to achieve its theoretical hydrogen storage capacity of $1.9 \mathrm{wt} \%$ [31-33]. As carbon materials such as graphite or CAs have been shown to reduce the hydrogen adsorption and desorption 
temperatures of $\mathrm{Mg}$ [34], it is not unreasonable to expect that CA addition could also be able to improve the hydrogen adsorption behavior of the FeTi system. There is a further advantage of using Pd-doped CAs as it has been shown that an addition of $1 \mathrm{wt} \% \mathrm{Pd}$ in the FeTi can effectively enhance its hydrogen adsorption capacity [31-33].

$\mathrm{X}$-ray absorption near edge structure (XANES)/extended X-ray absorption fine structure (EXAFS) spectroscopy offers a powerful tool to understand the oxidation states and fine structures of $\mathrm{Ti}$ atoms in the microstructure of metal hydride composites [35-38]. Thus, a thorough study of the location of $\mathrm{Ti}$ species in metal hydrides may be helpful to explain the enhancement of hydrogen adsorptive kinetics by identifying the compounds in the hydrides. XANES/EXAFS spectroscopy is also an excellent technique for characterizing the valency and local structure of Ti species in a complex Timetal hydride with short-range orders [37-41]. These studies are conducted to identify the optimum hydrogen storage capacity for hydrogen storage system. In this work, synthesis and characterization, and advantages/disadvantages of different metal-hydride systems such as $\mathrm{Mg}$, TiFe, or $\mathrm{Na}$ based metal hydrides, complex hydrides compounds, were investigated by field-emission scanning electron microscopy (FE-SEM), X-ray diffraction (XRD), and XANES/EXAFS spectroscopy. In addition, the adsorptive $\mathrm{H}_{2}$ storage capacity was also studied using a high-pressure thermogravimetric analyzer.

\section{Experimental}

2.1. Preparation of Metal-Doped Carbon Aerogels. Metalloaded organic aerogels were prepared following the method developed by Pekala [42] for resorcinol-formaldehyde aerogels. In a typical procedure, CA was synthesized by first stirring vigorously resorcinol (20.70 g), $\mathrm{Na}_{2} \mathrm{CO}_{3}$ (0.04 g), and equal amount of deionized water in a polypropylene jar at room temperature until resorcinol dissolved. Formaldehyde (30.94 g of purity $36.5 \%$ ) was then added to the solution, followed by $0.01 \mathrm{M} \mathrm{PdCl}_{2}$ (Reagent ACS R.D.H., Germany) to acquire the doping of palladium. The solution was left at room temperature for $24 \mathrm{~h}$, then at $323 \mathrm{~K}$ for the next $24 \mathrm{~h}$, and finally at $365 \mathrm{~K}$ for another $72 \mathrm{~h}$ to obtain a dark black monolith. The product was rinsed with acetone three times and soaked overnight at room temperature, yielding the hydrogel materials. After drying at room temperature, the hydrogels were isolated by heating in an oven at temperatures from 273 to $1,100 \mathrm{~K}$ under an Ar atmosphere for several hours to obtain the Pd-doped CAs.

2.2. Preparation of Metal Hydrides. As received $\mathrm{TiCl}_{3}$ (Aldrich, 99.99\%, anhydrous) was used as the catalyst precursor. Crystalline $\mathrm{NaAlH}_{4}$ (Fluka, 99.9\%) was purified by tetrahydrofuran (THF) (Aldrich, 99.9\%, anhydrous) solution and vacuum-dried while being filtered through $0.7 \mu \mathrm{m}$ filter paper to remove any residual $\mathrm{Al}$ powder and other solids from the solution. The purified $\mathrm{NaAlH}_{4}$ was mixed with the catalyst precursor in THF to produce a Ti-doped sample containing up to $20 \mathrm{~mol} \%$ metal (relative to either $\mathrm{Na}$ or $\mathrm{Al}$ ). The THF was evaporated while the $\mathrm{NaAlH}_{4}$ and catalyst precursor were mixed manually for about $30 \mathrm{~min}$, using a mortar and pestle, or until the sample appeared to be completely dry. A Ti-NaAlH $\mathrm{N}_{4}$ sample was then ball-milled for $2 \mathrm{~h}$ using a SPEX 8000 high-energy mixer/mill at a milling speed of $1,000 \mathrm{rpm}$, and the weight ratio of ball to powder was $10: 1.0 .5-1.0$ gram of sample was subjected to ball-milling each time in a $65 \mathrm{~cm}^{3}$ SUS 304 vial by $\mathrm{ZrO}_{2}$ balls of $1.3 \mathrm{~cm}$ in diameter. $\mathrm{Fe}$ - and Ti-doped $\mathrm{MgH}_{2}$ was prepared following Yao et al. [43], where $\mathrm{MgH}_{2}$ was obtained by heating $\mathrm{Mg}$ powders (Alfa Aesar) to $400^{\circ} \mathrm{C}$ in a hydrogen storage rig. $90 \mathrm{wt} \%$ conversion to $\mathrm{MgH}_{2}$ was achieved according to the volumetric calculations. 1.5-2.0 grams of nanophase iron powder $(100 \mathrm{~nm})$, Ti (Aldrich $\mathrm{Co})$, and $\mathrm{MgH}_{2}$ samples were mixed in the composition of $\mathrm{MgH}_{2}-5.0 \mathrm{wt} \%(2 \mathrm{Fe}+\mathrm{Ti}$, molar ratio) and mechanically ball-milled by using a $\mathrm{ZrO}_{2}$ ball mixer/mill (model SPEX 8000). The samples were subjected to ball-milling as described above for $2 \mathrm{~h}$, using a weight ratio of ball to powder of $8: 1$ The powder was then ballmilled again with $5.0 \mathrm{wt} \%$ of CAs for an additional $10 \mathrm{~h}$ at a milling speed of 1,000 rpm. All procedures described above were carried out in a flowing argon gas glove box to prevent the metal hydride samples from oxidation. The samples were then used for hydrogen adsorption property tests and microstructure characterization.

2.3. Hydrogen Adsorption Measurements. The hydrogen isotherms were measured gravimetrically at different temperatures using a method previously described by Eddaoudi et al. [44]. A Cahn Thermax 500 microgravimetric balance with a sensitivity of $1 \mu \mathrm{g}$ was used to measure the change in mass of samples suspended within a glass enclosure under a certain atmosphere. A pressure sensor, with a range of 0 to $68 \mathrm{~atm}\left(\right.$ at $1,000^{\circ} \mathrm{C}$ ) and sensitivity of $0.011 \mathrm{~atm}$, was used to measure the hydrogen pressure in the chamber. Samples were outgassed overnight until a constant mass was attained; these varied from 0.2 to $2.0 \mathrm{~g}$. Prior to admittance of argon gas, the entire chamber and manifold were evacuated overnight. The system was purged at room temperature three times with the argon gas before cooling to $77 \mathrm{~K}$, and gases were passed through a molecular sieve trap immersed in liquid nitrogen to remove any condensable impurities or moisture before being exposed to the sample. Pressures were measured with the range covering 1 to $30 \mathrm{~atm}$. Hydrogen was added incrementally, and data points were recorded when no further change in mass was observed. The dynamic hydrogen adsorption data on Pd-, Ti-, Fe-doped CAs, $\mathrm{NaAlH}_{4}$, or $\mathrm{MgH}_{2}$ batch adsorption experiments were also conducted at room temperature $(298 \mathrm{~K})$ and different pressures. The adsorbed amount of hydrogen was calculated after the buoyancy correction.

2.4. Characterization of Carbon Aerogels and Metal Hydrides. The morphologies, crystallinity, particle size distribution, and the compositions of as-synthesized metal hydrides and metal-doped CAs were determined by FE-SEM equipped with EDS (Hitachi, S-4700 Type II) and HR-TEM (Zeiss 
10C). XRD (MAC Science, MXP18) was performed to identify the phases and crystallinities in the samples. Complex of metallic hydride and CAs was scanned from 20 to $80^{\circ}(2 \theta)$ with a scan rate of $4^{\circ}(2 \theta) \mathrm{min}^{-1}$, and monochromatic $\mathrm{CuK}_{\alpha}$ radiation was used. The recorded specific peak intensities and $2 \theta$ values can be further identified by a computer database system (JCPDS). The surface areas of the CAs were measured by BET (Brunauer-Emmett-Teller) nitrogen adsorption (Micromeritics ASAP 2010 Instrument). For the BET surface area measurement, the samples were scraped from the sample tube substrate and powdered so as to avoid any influence from the steel tube. Prior to measurement, all samples were degassed at $423 \mathrm{~K}$ for $1 \mathrm{~h}$. For the calculation of the BET surface areas, the relative pressure range $P / P_{0}$ from 0.05 to 0.2 was used. The pore radius distribution was determined by Barrett, Joyner, and Halenda (BJH) method.

The XANES/EXAFS spectra were collected at BL16A1 and BL01C1 (SWLS) beamlines at the National Synchrotron Radiation Research Center (NSRRC) of Taiwan. The electron storage ring was operated with the energy of $1.5 \mathrm{GeV}$ and a current of $100-200 \mathrm{~mA}$. A Si(111) double crystal monochromator (DCM) was used for providing highly monochromatized photon beams with energies of 1 to $15 \mathrm{keV}$ (BL16A1) and 5 to $30 \mathrm{keV}$ (BL01C1) and resolving power $(E / \Delta E)$ of up to 7,000 . Data were collected in fluorescence or transmission mode with a Lytle ionization detector [39] for $\mathrm{Ti}(4,966 \mathrm{eV})$ and $\mathrm{Pd}(24,350 \mathrm{eV}) \mathrm{K}$-edge experiments at room temperature. The photon energy was calibrated by characteristic preedge peaks in the absorption spectra of $\mathrm{Ti}$ standards. The raw absorption data in the region of 50 to $200 \mathrm{eV}$ below the edge position were fit to a straight line using the least-square algorithms [37-40]. The XANES was extended to energy of the order of $50 \mathrm{eV}$ above the edge. The $k^{2}$-weighted and EXAFS spectra were Fourier transformed to $R$ space over the range between 2.5 and $12.5 \AA^{-1}$. The EXAFS data were analyzed by using the UWXAFS 3.0 program and FEFF 8.2 codes [37-41].

\section{Results and Discussion}

3.1. Morphology of Metal-Doped Carbon Aerogels and Metal Hydrides. The HR-TEM image and FE-SEM micrographs of metal hydride and CAs complexes synthesized are shown in Figure 1. Figure 1(a) is an HR-TEM observation of the $\mathrm{Pd}$-doped aerogel structure consisting of spherical primary $\operatorname{Pd}(0)$ nanoparticles. It can be seen that palladium particles of size 3 to $10 \mathrm{~nm}$ were uniformly distributed throughout the gel. FE-SEM micrograph in Figure 1(b) reveals the pellet-like or irregularly shaped $\mathrm{Ti}-\mathrm{NaAlH}_{4}$ crystalline nanoparticle, with diameters approximately $50-80 \mathrm{~nm}$. Correspondingly, $\mathrm{Fe}$ and $\mathrm{Ti}$ nanoparticles with an average diameter of 50 $80 \mathrm{~nm}$ were dispersed uniformly on the surface of the doped $\mathrm{MgH}_{2}$ surface as shown in Figure 1(c).

3.2. X-Ray Powder Diffraction. The structure of the compound was confirmed by structural refinement of X-ray diffraction patterns shown in Figure 2. The intensive peaks

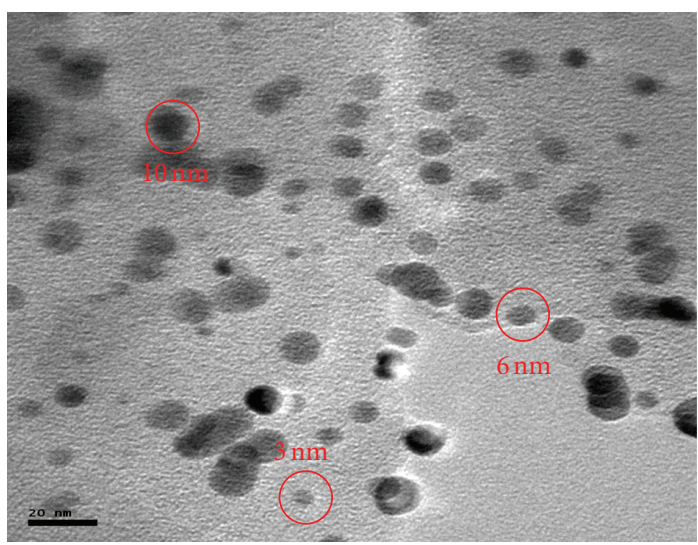

(a)

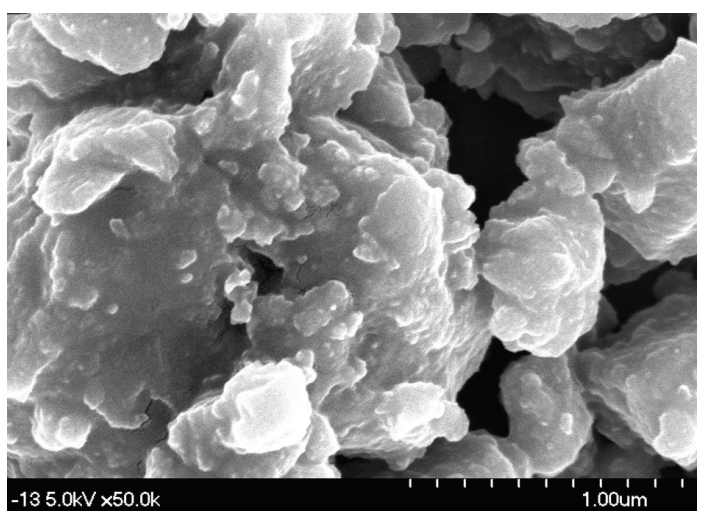

(b)

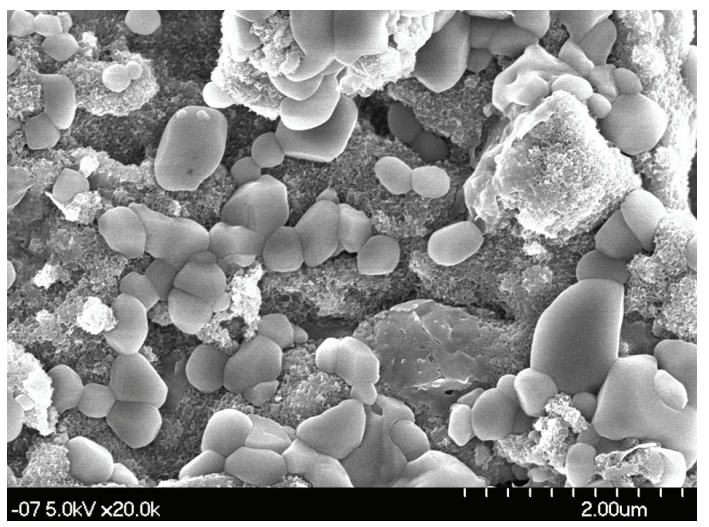

(c)

Figure 1: (a) HR-TEM image of $5 \mathrm{wt} \%$ Pd-doped carbon aerogels, FE-SEM microphotos of (b) $20 \mathrm{~mol} \% \mathrm{Ti}-\mathrm{NaAlH}_{4}$, and (c) $5 \mathrm{wt} \%$ FeTi-CAs- $\mathrm{MgH}_{2}(\mathrm{Fe}: \mathrm{Ti}=2: 1$, molar ratio).

appearing at small $2 \theta$ angles were characteristics of porous materials which possess numerous pores or cavities. Whereas Figure 2(a) shows the characteristic peaks of $2 \theta=27.46$, $31.75,45.53,56.54,66.29,75.36$, and $84.06^{\circ}$, respectively, which indicates that the structure of $\mathrm{Ti}-\mathrm{NaAlH}_{4}$ composites might not be affected by $\mathrm{Ti}$ added during ball-milling. From the intensity of (200) peak, the minimum grain size was measured to be around $60 \mathrm{~nm}$ [17-20]. This grain particle size was calculated from Scherrer's equation (with Warren's 


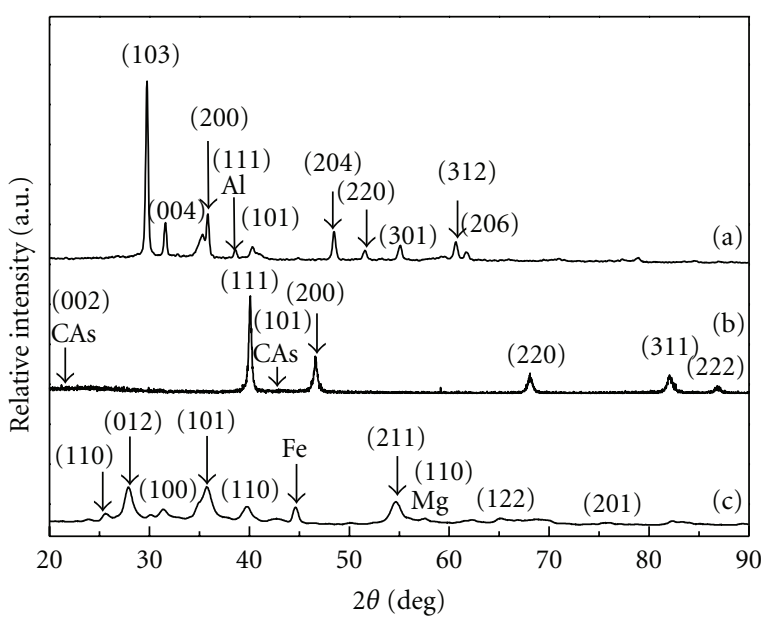

Figure 2: XRD patterns of (a) $20 \mathrm{~mol} \% \mathrm{Ti}-\mathrm{NaAlH}_{4}$, (b) $5 \mathrm{wt} \% \mathrm{Pd}-$ doped carbon aerogels, and (c) $5 \mathrm{wt} \% \mathrm{FeTi}-\mathrm{MgH}_{2}(\mathrm{Fe}: \mathrm{Ti}=2: 1$, molar ratio).

correction for instrumental broadening) applied to the halfheight of the maximum intensity diffraction peak. Metallic $\mathrm{Na}_{3} \mathrm{AlH}_{6}$ and $\mathrm{Al}$ were consistent with the characteristic peak at 32.92 and $38.6^{\circ}$, respectively [24]. From the FE-SEM measurement and XRD patterns, the titanium compound distributed on the surface of the $\mathrm{NaAlH}_{4}$ can be confirmed.

The X-ray diffraction patterns of the Pd-doped CAs indicate that the $\mathrm{Pd}$ nanoparticles have a crystalline structure (Figure 2(b)). According to FE-SEM micrographs, the well dispersion of metallic Pd nanoparticles in the CAs apparently facilitated the porous structure. The XRD patterns of Pddoped CAs show those two characteristic $2 \theta$ sharp peaks with higher intensities around 40.12 and $46.77^{\circ}$, indicating a largely crystalline structure. The mean particle size was about 5-8 nm from HR-TEM observation that may help the mesoporous structure of CAs to adsorb hydrogen. The diffraction angles at around 20 and $44^{\circ}$, corresponding to the (002) and (101) diffraction peaks of graphite, respectively, are represented in Figure 2(b). In addition, hexagonal structure of the CAs started to become disordered with the heat treatment, owning to the progressive graphitization of the sample. Figure 2(c) represents the XRD patterns of FeTi-doped $\mathrm{MgH}_{2}$ structure. The peak of the Fe sample at $44.6^{\circ}$ indicates that the decomposition of $\mathrm{Fe}$ onto the metal hydrides, whereas characteristic peaks of $\beta-\mathrm{MgH}_{2}$ were observed at $27.81,31.23,39.7,54.57,65.45$, and $75.54^{\circ}$, respectively. Thus, $\beta-\mathrm{MgH}_{2}$ morphology was dominated in the sample, and the metallic $\mathrm{Mg}$ with $\beta-\mathrm{MgH}_{2}$ structure represents the peaks at $36,57.76$, and $25.67^{\circ}$, respectively [43].

3.3. XANES and EXAFS. Figures $3(\mathrm{a})-3(\mathrm{e})$ show the preedge XANES spectra of Ti K-edge $(4,966 \mathrm{eV})$ in nanophase Ti$\mathrm{NaAlH}_{4}$ nanoparticles and anatase-typed $\mathrm{TiO}_{2}$ standard [45]. These spectra exhibit an absorbance feature of 4,966 eV for the $1 s$ to $3 d$ transition, which is forbidden by the selection rule in case of perfect octahedral symmetry. The sharp feature at $4,987 \mathrm{eV}$, due to the dipole allowed of $1 s$ to $3 p_{x y}$ electron transition, indicates the existence of Ti(IV). The

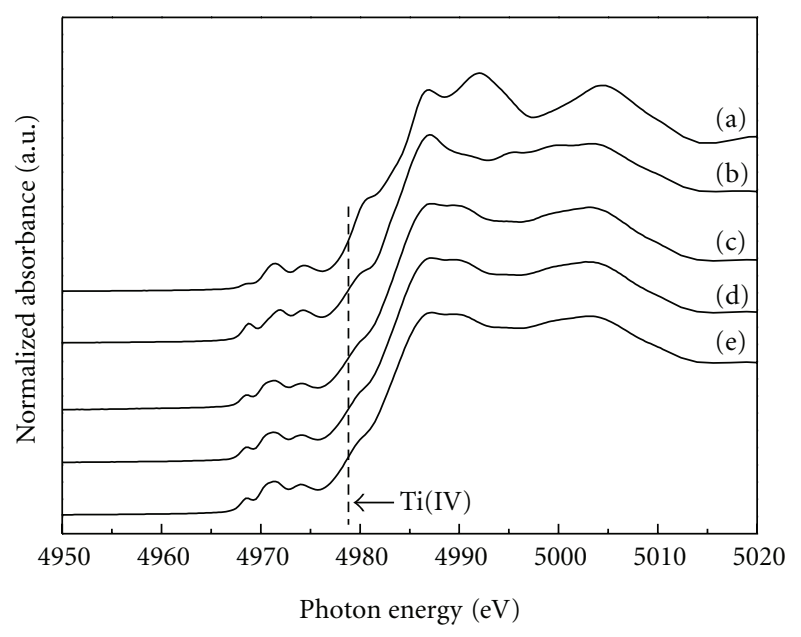

FIGURE 3: Ti K-edge XANES spectra of (a) rutile and (b) anatasetyped $\mathrm{TiO}_{2}$ standards; (c) 20 , (d) 12 , and (e) $8 \mathrm{~mol} \% \mathrm{Ti}-\mathrm{NaAlH}_{4}$ metal hydride composites after ball-milling for $2 \mathrm{~h}$ using a highenergy mixer/mill.

intensity of the $1 s$ to $3 p_{x y}$ transition is proportional to the population of $\mathrm{Ti}(\mathrm{IV})$ of the $\mathrm{Ti}-\mathrm{NaAlH}_{4}$ complexes. Oxygen atoms are the major atoms coordinated to the central $\mathrm{Ti}$

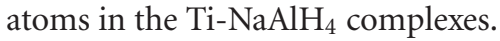

The reversible hydrogenation of $\mathrm{NaAlH}_{4}$ and dehydrogenation to $\mathrm{NaH}$ and $\mathrm{Al}$ occurred in two steps summarized as follows [1-6].

$$
\begin{array}{r}
3 \mathrm{NaAlH}_{4} \rightleftharpoons \mathrm{Na}_{3} \mathrm{AlH}_{6}+2 \mathrm{Al}+3 \mathrm{H}_{2} \quad 3.7 \mathrm{wt} \% \mathrm{H}_{2}, \\
2 \mathrm{Na}_{3} \mathrm{AlH}_{6} \rightleftharpoons 6 \mathrm{NaH}+2 \mathrm{Al}+3 \mathrm{H}_{2} \quad 1.9 \mathrm{wt} \% \mathrm{H}_{2} .
\end{array}
$$

Remarkably, the addition of the Ti species lowers the activation energy of the adsorption/desorption processes and enhanced the kinetic rates of these reactions by several orders of magnitude [46-50]. However, the exact mechanism still required further investigations. Notably, the hydrogendepleted multicomponent products resulting from (2) were found to form large crystallites of the complex metal hydride upon the reverse reaction in the presence of Ti during hydrogenation [45-47]. This is an important clue to understand the role of Ti where it implies a concerted migration of metal atoms over large distances. Local structural arrangements without the involvement of large-scale atomic migration would instead result in an amorphous or nanocrystalline structure.

The main scientific issues concerning the chemical forms (or speciation) of active species ultimately depend on molecular-scale structure and properties. Basic understanding at this scale is essential for further understanding the catalytic behaviors of $\mathrm{Ti}-\mathrm{NaAlH}_{4}$ complexes synthesized at different mol\% values of Ti. Generally, Ti K-edge EXAFS spectroscopy in Figure 4 can provide the information on the Ti atomic arrangement of catalysts in terms of bond distance, bond angle, coordination number, kind of near neighbors, and thermal or static disorders. Experimentally, the Ti species with a central $\mathrm{Ti}$ atom have a Ti-O bond 


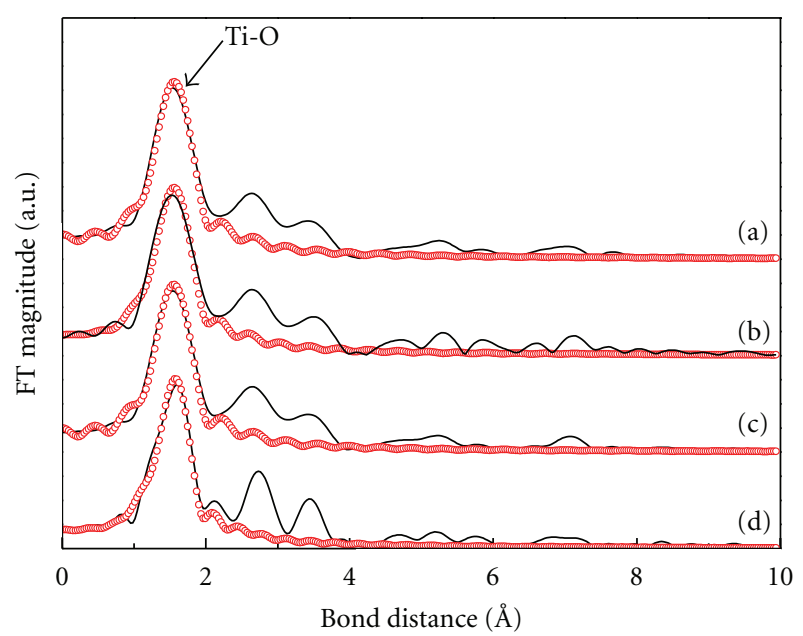

Figure 4: Fourier transformation (FT) spectra of (a) $\mathrm{Ti}^{-\mathrm{NaAlH}_{4}}$, (b) 20, (c) 12, and (d) $8 \mathrm{~mol} \% \mathrm{Ti}-\mathrm{NaAlH}_{4}$ metal hydride composites after ball-milling for $2 \mathrm{~h}$ using a high-energy mixer/mill. The best fitting of the EXAFS spectra are expressed by the dotted lines.

distance of $1.95 \pm 0.02 \AA$ and a coordination number of 4.07, in a Ti-NaAlH $\mathrm{T}_{4}$ composite after ball-milling for $2 \mathrm{~h}$ using a high-energy mixer/mill. Comparatively, however, a rutiletyped $\mathrm{TiO}_{2}$ has a central $\mathrm{Ti}$ atom with a Ti-Ti and a Ti(O)-Ti bonds, and their bond distances are $2.96 \pm 0.02 \AA$ and $3.57 \pm 0.02 \AA$, respectively [29-32, 40]. Since the differences of mass density $(\rho)$ and band structures between anatase- and rutile-typed $\mathrm{TiO}_{2}$, bond distances of Ti-O are $1.95 \pm 0.02 \AA$ and $1.93 \pm 0.02 \AA$, respectively [9-14].

The EXAFS data shown in Figure 4 reveals that the peak intensity of first-shell Ti-O bond increased with decreasing mol\% values of Ti-dopants for a $\mathrm{Ti}^{\mathrm{N}} \mathrm{NaAlH}+\mathrm{H}_{4}$ composite after ball-milling for $2 \mathrm{~h}$ using a high-energy mixer/mill. These results may offer a further explanation on the higher oxidation states of Ti species for a $\mathrm{Ti}-\mathrm{NaAlH}_{4}$ complex after ball-milling at higher rates and temperatures. Moreover, each $\mathrm{Ti}(\mathrm{IV})$ ion in the framework of nanophase $\mathrm{Ti}-\mathrm{NaAlH}_{4} \mathrm{com}-$ plex crystals is surrounded by six $\mathrm{O}^{2-}$ ions [9-14]. Since the bond lengths of the first and second shells for Ti-O bonding are $1.94 \pm 0.02 \AA$ and $1.97 \pm 0.02 \AA$, similarly with the coordination numbers of four and two, respectively, an octahedral structure of the $\mathrm{Ti}^{-\mathrm{NaAlH}_{4}}$ composites was found using EXAFS measurement [45]. As shown in Table 1 and Figure 5, the Ti species with a central $\mathrm{Ti}$ atom have a Ti-O bond distance of $2.81 \pm 0.02 \AA$ and a coordination number of 1.83 , in a Ti-NaAlH ${ }_{4}$ composite in $8 \mathrm{~mol} \% \mathrm{Ti}-\mathrm{NaAlH}_{4}$ metal hydride composites (more than $2 \mathrm{~mol} \%$ ) after the hydrogen adsorption processes. It can be seen that all Ti species in $\mathrm{Ti}-\mathrm{NaAlH}_{4}$ metal hydride composites can be reduced in the hydrogen adsorption processes and be kept in the metallic Ti form.

3.4. $\mathrm{N}_{2}$ Gas Adsorption Isotherms Analyses. Nonspecific physical adsorption of the CAs was carried out to measure the total surface area and pore size distribution for $\mathrm{Pd}$ doped CAs, as shown in Figure 6. The surface area, pore size distribution, and crystalline diameter of CAs were calculated according to the adsorption data summarized in Table 2. A large surface area was generally observed for Pd-doped CAs and beneficial characteristic for a great variety of applications. The microcrystalline structure of $\mathrm{Pd}$ on the CAs is confirmed from the HR-TEM analysis (Figure 1(a)), resulting in an increase of the surface area. The nitrogen adsorption-desorption isotherms exhibit a hysteresis behavior, indicating the microstructural nature of the porous specimens. Moreover, the type IV hysteresis isotherm obtained is represented in Figure 6(a). The adsorption hysteresis was observed in the region of a relative pressure $P / P_{0}$ above 0.4 . The specific surface areas of CAs and $\mathrm{Pd}$-doped CAs are 687 and $725 \mathrm{~m}^{2} \mathrm{~g}^{-1}$, with the pore volumes of 0.62 and $0.64 \mathrm{~cm}^{3} \mathrm{~g}^{-1}$, respectively, as shown in Table 2. It also indicates that these resulting factors of surface enhancement depended on the doping of the Pd on the CAs and consisted of higher porous structure $[49,50]$. These results may be caused by the dispersion of the Pd on the CAs surface and that indicated the metallic dispersion would be helpful for adsorption criteria.

The intensive peak of the $\operatorname{Pd}(0) \mathrm{K}$-edge region around $24,368 \mathrm{eV}$ and the stronger peak at $24,392 \mathrm{eV}$ were due to the orbital $3 d \rightarrow 5 s$ or $4 p$ hybridization caused by unoccupied $d$ bands, as shown in Figure 7 . These quantified the doping of $\mathrm{Pd}$ on the surface of carbon aerogels. Therefore, in the absorption where the orbital $3 d \rightarrow 5 s$ or $4 p$ hybridization was intensive, the $p$-like density of states was notably enhanced and the absorption increased like the second absorption peak in the XANES/EXAFS spectra of the Pd standards (Figures 7(b) and 8(a)). The structural parameters of the Pd powder and the palladium doped CAs, obtained from the best fit to the EXAFS data, are shown in Table 1. The coordination numbers and bond lengths also were well compared with the Pd metal and palladium-doped CAs crystal structure data. The Debye-Waller factors $\left(\Delta \sigma^{2}\right)$ were less than $0.015\left(\AA^{2}\right)$, which indicated that the palladium confirmatively has center $\mathrm{Pd}$ atoms coordinated by $\mathrm{Pd}-\mathrm{Pd}$ bonding. The bulk Pd metal possessed Pd-Pd bond distance of $2.74 \AA \pm 0.02 \AA$ and a coordination number of 9.59. For comparison, fresh CAs-Pd clusters were found to have a Pd-Pd bond distance of $2.12 \AA$ with a coordination number of 6.18 . This shortening of the bond distance with a lower coordination number was caused by random motion of surface atom on the small Pd particles and was responsible for the increase in the surface area of the palladium doped CAs samples, whereas hydrogen reduced bulk CA-doped Pd cluster consisted with the Pd-Pd bond distance of $2.73 \AA$ and a coordination number of 9.23. This revealed that the $\mathrm{Pd}$ nanoparticles were notably activated in the reduction process [48]. Moreover, the shortening of the bond distance with coordination number probably was caused by the random motion of surface atom on the small $\mathrm{Pd}$ particles and therefore increases the surface area of the Pd-doped CAs samples. Furthermore, this result also revealed that the $\mathrm{Pd}$ nanoparticles were well dispersed on the surface of CAs, which might improve the amount of hydrogen storage efficiency significantly.

3.5. Hydrogen Gas Adsorption Isotherms Analyses. Comparisons of the hydrogen adsorption of metal hydride and 
TABle 1: Fine structural parameters $\mathrm{Pd} / \mathrm{Ti}$ atoms in $\mathrm{Pd} / \mathrm{Ti}$ powder standards, $5 \mathrm{wt} \% \mathrm{Pd}$-doped carbon aerogels with or without hydrogen reduction, and $20 \mathrm{~mol} \% \mathrm{Ti}-\mathrm{NaAlH}_{4}$ metal hydride composites analyzed by using EXAFS.

\begin{tabular}{|c|c|c|c|c|}
\hline Samples & Shell & $\mathrm{CN}^{\mathrm{a}}( \pm 0.05)$ & $R^{\mathrm{b}}( \pm 0.02 \AA)$ & $\sigma^{2}\left(\AA^{2}\right)^{\mathrm{c}}$ \\
\hline \multicolumn{5}{|l|}{ Pd species } \\
\hline Pd powder standard & $\mathrm{Pd}-\mathrm{Pd}$ & 9.59 & 2.74 & 0.0056 \\
\hline Fresh 5 wt $\%$ Pd-doped CAs ${ }^{d}$ & $\mathrm{Pd}-\mathrm{O}$ & 6.18 & 2.12 & 0.0061 \\
\hline $\mathrm{H}_{2}$ reduced 5 wt $\%$ Pd-doped CAs ${ }^{\mathrm{e}}$ & $\mathrm{Pd}-\mathrm{Pd}$ & 9.23 & 2.73 & 0.0073 \\
\hline \multicolumn{5}{|l|}{ Ti species } \\
\hline Metallic Ti standard & $\mathrm{Ti}-\mathrm{Ti}$ & 1.78 & 2.93 & 0.0044 \\
\hline TiO standard & $\mathrm{Ti}-\mathrm{O}$ & 2.14 & 2.53 & 0.0083 \\
\hline $\mathrm{Ti}_{2} \mathrm{O}_{3}$ standard & $\mathrm{Ti}-\mathrm{O}$ & 3.02 & 2.12 & 0.0023 \\
\hline Rutile-typed $\mathrm{TiO}_{2}$ standard & $\mathrm{Ti}-\mathrm{O}$ & 4.11 & 1.94 & 0.0015 \\
\hline Anatase-typed $\mathrm{TiO}_{2}$ standard & $\mathrm{Ti}-\mathrm{O}$ & 4.15 & 1.93 & 0.0026 \\
\hline Ball-milled 20 mol\% Ti-NaAlH ${ }_{4}$ & $\mathrm{Ti}-\mathrm{O}$ & 4.07 & 1.95 & 0.0048 \\
\hline $\mathrm{H}_{2}$-adsorbed $20 \mathrm{~mol} \% \mathrm{Ti}-\mathrm{NaAlH}_{4}$ & $\mathrm{Ti}-\mathrm{Ti}$ & 1.83 & 2.81 & 0.0051 \\
\hline
\end{tabular}

${ }^{a} \mathrm{CN}$ denotes "coordination number";

${ }^{b} R$ denotes "bond distance";

${ }^{c} \sigma$ denotes "Debye-Waller factor";

${ }^{\mathrm{d}}$ Fresh $5 \mathrm{wt} \%$ Pd-doped carbon aroegel samples denote the as-synthesized materials that were oxidized and converted into PdO species instantly in the synthetic processes;

e $5 \mathrm{wt} \%$ Pd-doped carbon aroegel samples were reduced at $453 \mathrm{~K}$ under flowing hydrogen gas for six hours.

TABLE 2: Values of specific surface area and pore size distribution of as-synthesized carbon aerogel samples calculated using BET or BJH nitrogen isotherms method.

\begin{tabular}{lcc}
\hline Samples & $S_{\mathrm{BET}}{ }^{\mathrm{a}}\left(\mathrm{m}^{2} \mathrm{~g}^{-1}\right)$ & $V_{t}^{\mathrm{b}}\left(\mathrm{cm}^{3} \mathrm{~g}^{-1}\right)$ \\
\hline Carbon aerogel & 687 & 0.69 \\
$5 \mathrm{wt} \%$ Pd-doped carbon areogel & 725 & 0.71 \\
\hline
\end{tabular}

${ }^{a} S_{\text {BET }}$ : specific surface area computed and calculated by using BET nitrogen isotherms equation;

${ }^{\mathrm{b}} V_{t}$ : total pore volume estimated and calculated at a related pressure of 0.98 by using $\mathrm{BJH}$ nitrogen isotherms equation.

doped metal hydride with carbon aerogel are given in Figures 9(a)-9(e). Under a typical reaction condition of $298 \mathrm{~K}$ and 1-30 atm, the hydrogen adsorption curves of pure $\mathrm{MgH}_{2}$ (Figure 9(e)) were consistent with lowest adsorption criteria, whereas the FeTi with CA-doped $\mathrm{MgH}_{2}$ (Figure 9(a)) possessed the highest hydrogen adsorption capacity of $4.02 \mathrm{wt} \%$. Mesoporous structure of the CAs, which has a very high surface area as confirmed from the BET nitrogen isotherm analysis, improved the hydrogen adsorption behavior. This is inline with the finding of Imamura et al. [34], who reported that the uptake of hydrogen in a C-Mg composite took place at a significantly lower temperature than that in pure magnesium. Similarly, Jung et al. [51] suggested that the faster adsorption kinetics of $\mathrm{MgH}_{2}$ systems may result from the very high defect densities of the damaged $\mathrm{MgH}_{2}$ surfaces caused by the ball-milling of $\mathrm{Mg}$ with hard and small oxide particles. Defects provide hydrogen an easy path to go into $\mathrm{Mg}$ powders. Therefore, the hydrogen adsorption capacity of $2.7 \mathrm{wt} \%$ was obtained with the addition of FeTi nanoparticles into the $\mathrm{MgH}_{2}$ samples by ball-milling (Figure 9(b)). Thus, minute particles of FeTi were found to be the most useful catalyst to improve the hydrogen adsorption properties of $\mathrm{MgH}_{2}$. Nitrogen adsorption by the

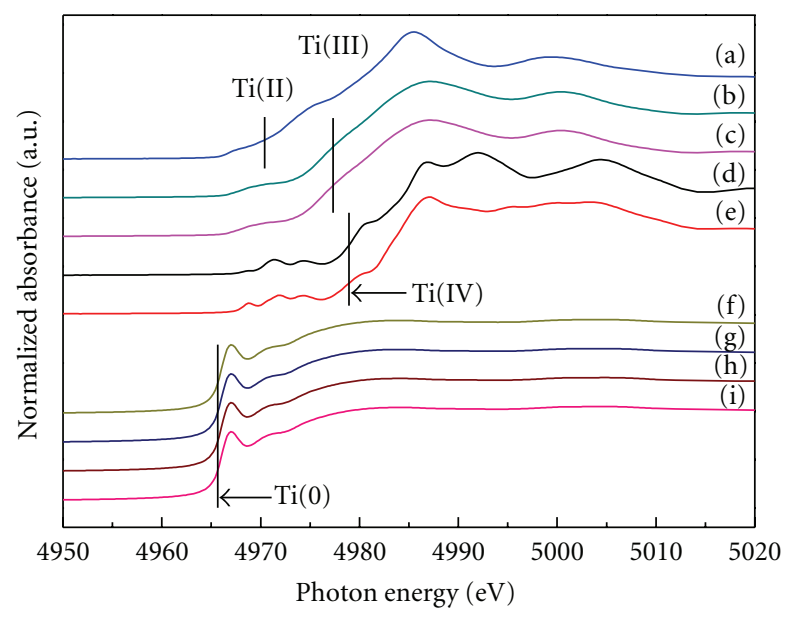

FIgure 5: Ti K-edge XANES spectra of (a) $\mathrm{TiO}$, (b) $\mathrm{Ti}_{2} \mathrm{O}_{3}$, (c) $\mathrm{TiCl}_{3}$, (d) rutile-, (e) anatase-typed $\mathrm{TiO}_{2}$ standards, (f) metallic Ti standard; (g) 20, (h) 12, and (i) $8 \mathrm{~mol} \% \mathrm{Ti}-\mathrm{NaAlH}_{4}$ metal hydride composites after the hydrogen adsorption processes.

CAs or Pd-doped CAs material clearly shows reversible type IV isotherms at each of the activation stages, indicative of permanent porosity in Figure 6(a). The selectivity of $\mathrm{H}_{2}$ adsorption over Pd-doped CAs was $1.6 \mathrm{wt} \%$, as shown in Figure 9(c). Due to the doping of Pd on CAs, access of hydrogen was easier in the vacancies created by the mesoporous structure with a higher surface area that was confirmed with the BET nitrogen isotherms measurement. In addition, this suggests that an antidispersive force plays an important role in case of Pd-doped CAs samples and the expected specific interaction with Pd active sites. Thus, this work confirmed that metal doping by Pd on CAs may improve the hydrogen adsorption criteria. An intriguing observation concerns the dependence of the rehydrogenation 


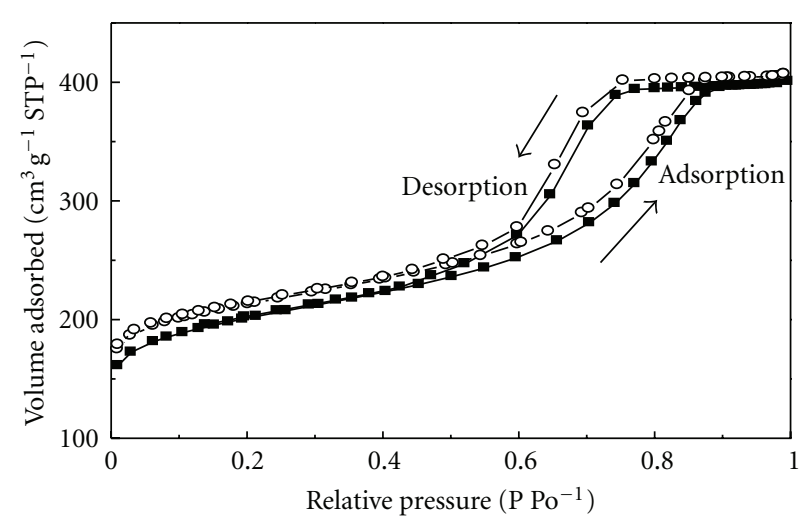

(a)

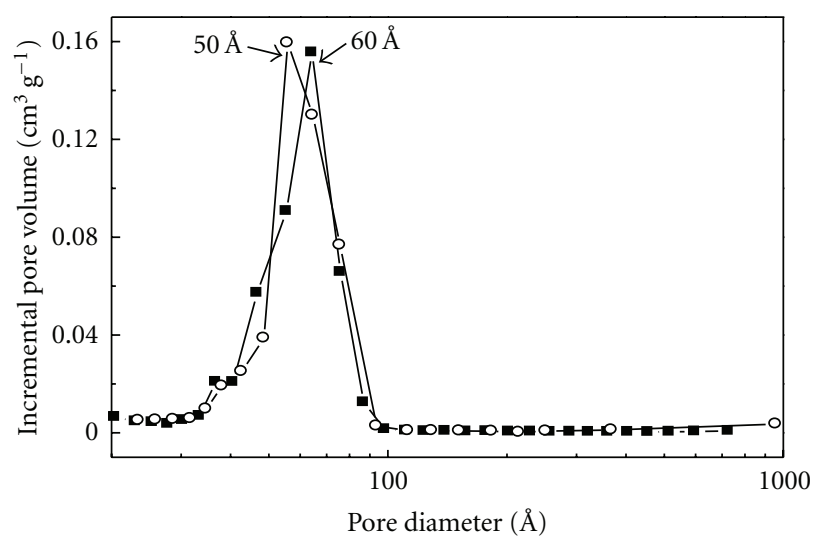

(b)

FIGURE 6: (a) Nitrogen adsorption/desorption isotherms and (b) pore size distribution for the as-synthesized ( $\mathbf{\square})$ carbon aerogels, and ( $\bigcirc$ ) $5 \mathrm{wt} \% \mathrm{Pd}$-doped carbon aerogels. Arrow mark in the upward direction is the adsorption process and downward is the desorption process, respectively.

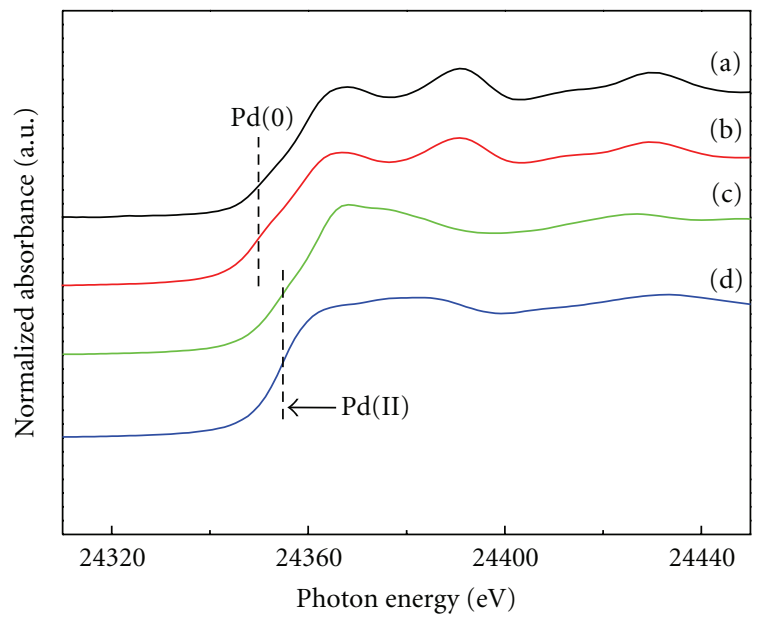

Figure 7: Pd K-edge XANES spectra of (a) $5 \mathrm{wt} \%$ Pd-CAs, (b) metallic $\mathrm{Pd},(\mathrm{c}) \mathrm{PdO}$, and (d) $\mathrm{PdCl}_{2}$ standards.

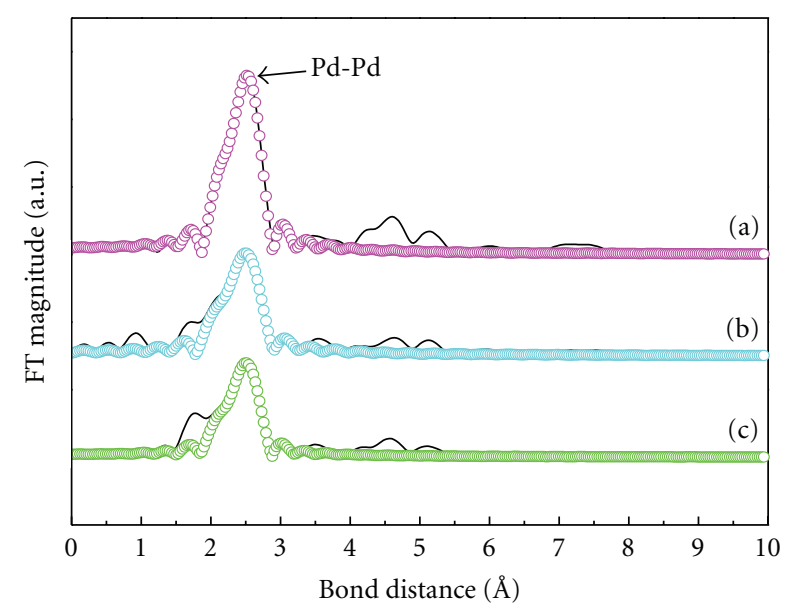

Figure 8: Fourier transformation (FT) spectra of (a) $5 \mathrm{wt} \% \mathrm{Pd}-$ CAs, (b) metallic $\mathrm{Pd}$, (c) $\mathrm{PdO}$, and (d) $\mathrm{PdCl}_{2}$ standards. The best fitting of the EXAFS spectra is expressed by the dotted lines.

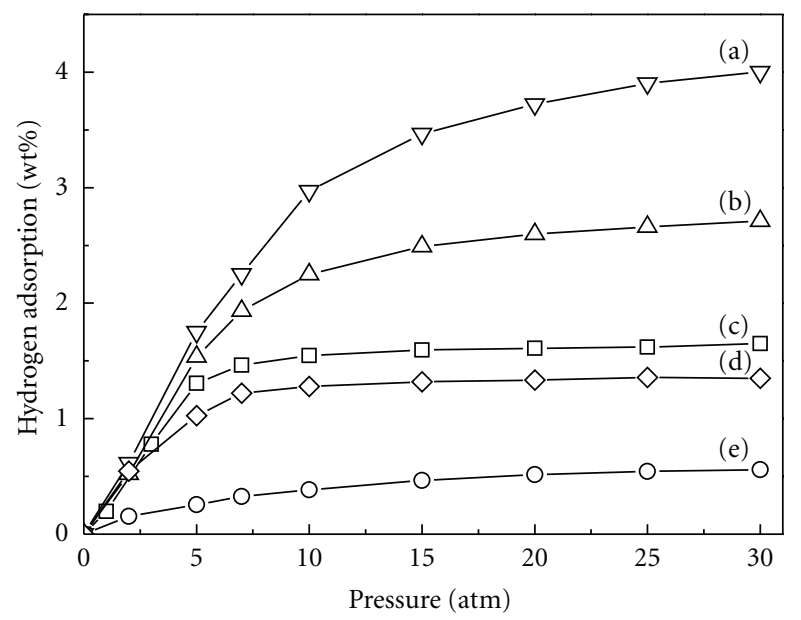

Figure 9: Hydrogen adsorption curves of (a) $5 \mathrm{wt} \%$ FeTi-CAs$\mathrm{MgH}_{2}\left(\mathrm{Fe}: \mathrm{Ti}=2: 1\right.$, molar ratio), (b) $5 \mathrm{wt} \% \mathrm{FeTi}-\mathrm{MgH}_{2}(\mathrm{Fe}: \mathrm{Ti}=$ $2: 1$, molar ratio), (c) $5 \mathrm{wt} \% \mathrm{Pd}-\mathrm{CAs}$, (d) $8 \mathrm{~mol} \% \mathrm{Ti}-\mathrm{NaAlH}_{4}$, and (e) fresh $\mathrm{MgH}_{2}$. The pressures of hydrogen adsorption processes for as-synthesized metal hydride composites ranged from 1-30 atm.

kinetics on the amount of Ti doping. Moreover, as shown in Figure 9(a), it was observed that the hydrogen uptakes of FeTi-CAs- $\mathrm{MgH}_{2}$ systems could be enhanced markedly by the phenomenon of "hydrogen spillover" via a simple technique for building carbon bridges [52]. One of the possible reasons is that the hydrogen molecules do not readily dissociate on $\mathrm{Mg}$ surface. Experimentally, the catalytic effect was found on hydrogen adsorption of mixing transition metal of Ti atoms into $\mathrm{Mg}$ hydride powder during ball-milling. The likely mechanism proposed for the FeTi-CAs- $\mathrm{MgH}_{2}$ hetero-structures can be also summarized concisely: (1) adsorption of hydrogen on the Ti surface, (2) dissociation of hydrogen and chemisorption of atomic hydrogen on the surface, (3) migration of atomic hydrogen onto the CAs support, and finally (4) chemisorptive spillover onto the 
$\mathrm{MgH}_{2}$ substrate. In addition, spillover is facilitated through the use of a carbon bridging compound between the Ti/CAs complex and the $\mathrm{MgH}_{2}$ substrate. Typically, an $8 \mathrm{~mol} \% \mathrm{Ti}$ dop onto the NaAlH4 (Figure $9(\mathrm{~d})$ ) revealed the maximum hydrogen adsorption capacity of $1.2 \mathrm{wt} \%$ within this class of adsorptive materials. In addition, perfect single crystal $\mathrm{TiO}_{2}$ was inert toward reaction with $\mathrm{H}_{2}$ [51]. However, $\mathrm{H}_{2}$ was absorbed by $\mathrm{TiO}_{2}$-surfaces that contained a higher density of defects in the crystal structure. Therefore, surface of $\mathrm{MgH}_{2}$ in the presence of the metal-doped $\mathrm{Fe}$ and $\mathrm{Ti}$ with CAs created a high defect density that introduced a higher hydrogen adsorption behavior in the adsorption or desorption processes.

\section{Conclusions}

The synthesis, characterization, and $\mathrm{H}_{2}$ adsorption capacity of CAs/metallic hydride nanocomposites as a catalyst were investigated in the present work. Experimentally, the $\mathrm{H}_{2}$ storage capacity of metallic samples was conducted and measured by a TGA microbalance method. In addition, fine structures and crystallinity of metallic hydride were identified by BET nitrogen adsorption isotherms, HR-TEM, FE-SEM/EDS, XRD, and XANES/EXAFS. The CAs were very effective in improving the hydrogen storage capacity of the $\mathrm{Fe}-$, Ti-doped $\mathrm{MgH}_{2}$ samples with the "hydrogen spillover" route. Metallic dispersion such as $\mathrm{Pd}$ nanoparticles onto the CAs may improve the hydrogen adsorption abilities. Higher surface area from CAs and the defect criteria of the $\mathrm{MgH}_{2}$ surface due to the doping of the metallic particle caused to improve the hydrogen adsorption capacities. On the other hand, Ti-doping onto the sodium aluminum hydride can only improve slightly the hydrogen storage capabilities.

\section{Acknowledgment}

The authors gratefully acknowledge the financial support of National Science Council (Contract no. NSC-95-2623-7155-011) of Taiwan.

\section{References}

[1] W. Lohstroh, M. Fichtner, and W. Breitung, "Complex hydrides as solid storage materials: first safety tests," International Journal of Hydrogen Energy, vol. 34, no. 14, pp. 59815985, 2009.

[2] J. Brouwer, "On the role of fuel cells and hydrogen in a more sustainable and renewable energy future," Current Applied Physics, vol. 10, no. 2, pp. S9-S17, 2010.

[3] M. Fichtner, O. Fuhr, O. Kircher, and J. Rothe, "Small Ti clusters for catalysis of hydrogen exchange in $\mathrm{NaAlH}_{4}$," Nanotechnology, vol. 14, no. 7, pp. 778-785, 2003.

[4] F. S. Yang, G. X. Wang, Z. X. Zhang, X. Y. Meng, and V. Rudolph, "Design of the metal hydride reactors-a review on the key technical issues," International Journal of Hydrogen Energy, vol. 35, no. 8, pp. 3832-3840, 2010.

[5] E. Rönnebro, "High-pressure techniques for discovering and re-hydrogenation of metal hydride materials," Journal of Physics and Chemistry of Solids, vol. 71, no. 8, pp. 1154-1158, 2010 .
[6] H. W. Brinks, C. M. Jensen, S. S. Srinivasan, B. C. Hauback, D. Blanchard, and K. Murphy, "Synchrotron X-ray and neutron diffraction studies of $\mathrm{NaAlH}_{4}$ containing Ti additives," Journal of Alloys and Compounds, vol. 376, no. 1-2, pp. 215-221, 2004.

[7] D. J. Ross, M. D. Halls, A. G. Nazri, and R. F. Aroca, "Raman scattering of complex sodium aluminum hydride for hydrogen storage," Chemical Physics Letters, vol. 388, no. 4-6, pp. 430435, 2004.

[8] R. A. Varin, T. Czujko, C. Chiu, R. Pulz, and Z. S. Wronski, "Synthesis of nanocomposite hydrides for solid-state hydrogen storage by controlled mechanical milling techniques," Journal of Alloys and Compounds, vol. 483, no. 1-2, pp. 252-255, 2009.

[9] P. Wang and C. M. Jensen, "Preparation of Ti-doped sodium aluminum hydride from mechanical milling of $\mathrm{NaH} / \mathrm{AI}$ with off-the-shelf Ti powder," Journal of Physical Chemistry B, vol. 108, no. 40, pp. 15827-15829, 2004.

[10] E. Bruster, T. A. Dobbins, R. Tittsworth, and D. Anton, "Decomposition behavior of Ti-doped $\mathrm{NaAlH}_{4}$ studied using X-ray absorption spectroscopy at the titanium K-edge," in Proceedings of the Materials Research Society Symposium, pp. 47-52, December 2004.

[11] O. Kircher and M. Fichtner, "Kinetic studies of the decomposition of $\mathrm{NaAlH}_{4}$ doped with a Ti-based catalyst," Journal of Alloys and Compounds, vol. 404-406, pp. 339-342, 2005.

[12] I. P. Jain, P. Jain, and A. Jain, "Novel hydrogen storage materials: a review of lightweight complex hydridespuye," Journal of Alloys and Compounds, vol. 503, no. 2, pp. 303-339, 2010.

[13] R. Krishnan, D. Agrawal, and T. Dobbins, "Microwave irradiation effects on reversible hydrogen desorption in sodium aluminum hydrides $\left(\mathrm{NaAlH}_{4}\right)$," Journal of Alloys and Compounds, vol. 470, no. 1-2, pp. 250-255, 2009.

[14] X. Fan, X. Xiao, J. Hou et al., "Reversible hydrogen storage behaviors and microstructure of TiC-doped sodium aluminum hydride," Journal of Materials Science, vol. 44, no. 17, pp. 4700-4704, 2009.

[15] J. W. Kim, J. H. Shim, S. C. Kim et al., "Catalytic effect of titanium nitride nanopowder on hydrogen desorption properties of $\mathrm{NaAlH}_{4}$ and its stability in $\mathrm{NaAlH}_{4}$," Journal of Power Sources, vol. 192, no. 2, pp. 582-587, 2009.

[16] Z. Xueping, L. Shenglin, and L. Donglin, "The effect of additives on the hydrogen storage properties of $\mathrm{NaAlH}_{4}$," International Journal of Hydrogen Energy, vol. 34, no. 6, pp. 2701-2704, 2009.

[17] P. Wang, X. D. Kang, and H. M. Cheng, "Exploration of the nature of active Ti species in metallic Ti-doped $\mathrm{NaAlH}_{4}$," Journal of Physical Chemistry B, vol. 109, no. 43, pp. 2013120136, 2005.

[18] S. Zhang, C. Lu, N. Takeichi, T. Kiyobayashi, and N. Kuriyama, "Reaction stoichiometry between $\mathrm{TiCl} 3$ and $\mathrm{NaAlH}_{4}$ in Tidoped alanate for hydrogen storage: the fate of the titanium species," International Journal of Hydrogen Energy, vol. 36, no. 1, pp. 634-638, 2011.

[19] H. W. Brinks, B. C. Hauback, S. S. Srinivasan, and C. M. Jensen, "Synchrotron X-ray studies of Al1-yTiy formation and re-hydriding inhibition in Ti-enhanced $\mathrm{NaAlH}_{4}$," Journal of Physical Chemistry B, vol. 109, no. 33, pp. 15780-15785, 2005.

[20] E. H. Majzoub, J. L. Herberg, R. Stumpf, S. Spangler, and R. S. Maxwell, "XRD and NMR investigation of Ti-compound formation in solution-doping of sodium aluminum hydrides: solubility of Ti in $\mathrm{NaAlH}_{4}$ crystals grown in THF," Journal of Alloys and Compounds, vol. 394, no. 1-2, pp. 265-270, 2005.

[21] T. Schmidt and L. Röntzsch, "Reversible hydrogen storage in Ti-Zr-codoped $\mathrm{NaAlH}_{4}$ under realistic operation conditions," Journal of Alloys and Compounds, vol. 496, no. 1-2, pp. L38-L40, 2010. 
[22] M. Onkawa, S. Zhang, H. T. Takeshita, N. Kuriyama, and T. Kiyobayashi, "Dehydrogenation kinetics of Ti-doped $\mathrm{NaAlH}_{4}$-influence of Ti precursors and preparation methods," International Journal of Hydrogen Energy, vol. 33, no. 2, pp. 718-721, 2008.

[23] X. Xiao, L. Chen, X. Wang, Q. Wang, and C. Chen, "The hydrogen storage properties and microstructure of Ti-doped sodium aluminum hydride prepared by ball-milling," International Journal of Hydrogen Energy, vol. 32, no. 13, pp. 24752479, 2007.

[24] C. Milanese, A. Girella, G. Bruni et al., "Hydrogen storage in magnesium-metal mixtures: reversibility, kinetic aspects and phase analysis," Journal of Alloys and Compounds, vol. 465, no. 1-2, pp. 396-405, 2008.

[25] M. Danaie, S. X. Tao, P. Kalisvaart, and D. Mitlin, "Analysis of deformation twins and the partially dehydrogenated microstructure in nanocrystalline magnesium hydride $\left(\mathrm{MgH}_{2}\right)$ powder," Acta Materialia, vol. 58, no. 8, pp. 3162-3172, 2010.

[26] R. Domènech-Ferrer, M. Gurusamy Sridharan, G. Garcia, F. $\mathrm{Pi}$, and J. Rodríguez-Viejo, "Hydrogenation properties of pure magnesium and magnesium-aluminium thin films," Journal of Power Sources, vol. 169, no. 1, pp. 117-122, 2007.

[27] K. J. Jeon, A. Theodore, and C. Y. Wu, "Enhanced hydrogen absorption kinetics for hydrogen storage using $\mathrm{Mg}$ flakes as compared to conventional spherical powders," Journal of Power Sources, vol. 183, no. 2, pp. 693-700, 2008.

[28] S. G. Chalk and J. F. Miller, "Key challenges and recent progress in batteries, fuel cells, and hydrogen storage for clean energy systems," Journal of Power Sources, vol. 159, no. 1, pp. 73-80, 2006.

[29] I. E. Malka, T. Czujko, and J. Bystrzycki, "Catalytic effect of halide additives ball milled with magnesium hydride," International Journal of Hydrogen Energy, vol. 35, no. 4, pp. 1706-1712, 2010.

[30] B. Sakintuna, F. Lamari-Darkrim, and M. Hirscher, "Metal hydride materials for solid hydrogen storage: a review," International Journal of Hydrogen Energy, vol. 32, no. 9, pp. 1121-1140, 2007.

[31] J. Wang, A. D. Ebner, R. Zidan, and J. A. Ritter, "Synergistic effects of co-dopants on the dehydrogenation kinetics of sodium aluminum hydride," Journal of Alloys and Compounds, vol. 391, no. 1-2, pp. 245-255, 2005.

[32] S. Chaudhuri and J. T. Muckerman, "First-principles study of Ti-catalyzed hydrogen chemisorption on an Al surface: a critical first step for reversible hydrogen storage in $\mathrm{NaAlH} 4$," Journal of Physical Chemistry B, vol. 109, no. 15, pp. 69526957, 2005.

[33] E. H. Majzoub, J. L. Herberg, R. Stumpf, S. Spangler, and R. S. Maxwell, "XRD and NMR investigation of Ti-compound formation in solution-doping of sodium aluminum hydrides: solubility of Ti in $\mathrm{NaAlH}_{4}$ crystals grown in THF," Journal of Alloys and Compounds, vol. 394, no. 1-2, pp. 265-270, 2005.

[34] H. Imamura, Y. Takesue, S. Tabata, N. Shigetomi, Y. Sakata, and S. Tsuchiya, "Hydrogen storage composites obtained by mechanical grinding of magnesium with graphite carbon," Chemical Communications, no. 22, pp. 2277-2278, 1999.

[35] S. Carter, A. S. Fisher, P. S. Goodall, M. W. Hinds, S. Lancaster, and S. Shore, "Atomic spectrometry update. Industrial analysis: metals, chemicals and advanced materials," Journal of Analytical Atomic Spectrometry, vol. 25, no. 12, pp. 1808-1858, 2010.

[36] A. Léon, O. Kircher, M. Fichtner, J. Rothe, and D. Schild, "Evolution of the local structure around Ti atoms in $\mathrm{NaAlH}_{4}$ doped with $\mathrm{TiCl}_{3}$ or $\mathrm{Ti}_{13} \cdot 6 \mathrm{THF}$ by ball milling using X-ray absorption and X-ray photoelectron spectroscopy," Journal of Physical Chemistry B, vol. 110, no. 3, pp. 1192-1200, 2006.

[37] P. Canton, M. Fichtner, C. Frommen, and A. Léon, "Synchrotron X-ray studies of Ti-doped $\mathrm{NaAlH}_{4}$," Journal of Physical Chemistry B, vol. 110, no. 7, pp. 3051-3054, 2006.

[38] A. Léon, A. Balerna, G. Cinque, C. Frommen, and M. Fichtner, "Al K edge XANES measurements in $\mathrm{NaAlH}_{4}$ doped with TiCl 3 by ball milling," Journal of Physical Chemistry C, vol. 111, no. 9, pp. 3795-3798, 2007.

[39] F. W. Lytle, "The EXAFS family tree: a personal history of the development of extended X-ray absorption fine structure," Journal of Synchrotron Radiation, vol. 6, no. 3, pp. 123-134, 1999.

[40] S. D. Conradson, "Application of X-ray absorption fine structure spectroscopy to materials and environmental science," Applied Spectroscopy, vol. 52, no. 7, pp. 252A-279A, 1998.

[41] G. Vlaic, D. Andreatta, and P. E. Colavita, "Characterisation of heterogeneous catalysts by EXAFS," Catalysis Today, vol. 41, no. 1-3, pp. 261-275, 1998.

[42] R. W. Pekala, "Organic aerogels from the polycondensation of resorcinol with formaldehyde," Journal of Materials Science, vol. 24, no. 9, pp. 3221-3227, 1989.

[43] X. Yao, C. Wu, A. Du et al., "Mg-based nanocomposites with high capacity and fast kinetics for hydrogen storage," Journal of Physical Chemistry B, vol. 110, no. 24, pp. 11697-11703, 2006.

[44] M. Eddaoudi, H. Li, and O. M. Yaghi, "Highly porous and stable metal-organic frameworks: structure design and sorption properties," Journal of the American Chemical Society, vol. 122, no. 7, pp. 1391-1397, 2000.

[45] C. P. Baldé, A. M. J. van der Eerden, H. A. Stil, F. M. F. de Groot, K. P. de Jong, and J. H. Bitter, "On the local structure of Ti during in situ desorption of $\mathrm{Ti}(\mathrm{OBu})_{4}$ and $\mathrm{TiCl}_{3}$ doped $\mathrm{NaAlH}_{4}$," Journal of Alloys and Compounds, vol. 446-447, pp. 232-236, 2007.

[46] J. Wang, A. D. Ebner, T. Prozorov, R. Zidan, and J. A. Ritter, "Effect of graphite as a co-dopant on the dehydrogenation and hydrogenation kinetics of Ti-doped sodium aluminum hydride," Journal of Alloys and Compounds, vol. 395, no. 1-2, pp. 252-262, 2005.

[47] T. Vegge, "Equilibrium structure and Ti-catalyzed $\mathrm{H}_{2}$ desorption in $\mathrm{NaAlH}_{4}$ nanoparticles from density functional theory," Physical Chemistry Chemical Physics, vol. 8, no. 42, pp. 48534861, 2006.

[48] Y. Yamamoto, T. Matsuzaki, K. Ohdan, and Y. Okamoto, "Structure and electronic state of $\mathrm{PdCl}_{2}-\mathrm{CuCl}_{2}$ catalysts supported on activated carbon," Journal of Catalysis, vol. 161, no. 2, pp. 577-586, 1996.

[49] S. Cacchi, C. L. Cotet, G. Fabrizi et al., "Efficient hydroxycarbonylation of aryl iodides using recoverable and reusable carbon aerogels doped with palladium nanoparticles as catalyst," Tetrahedron, vol. 63, no. 11, pp. 2519-2523, 2007.

[50] L. C. Cotet, M. Gich, A. Roig et al., "Synthesis and structural characteristics of carbon aerogels with a high content of $\mathrm{Fe}$, $\mathrm{Co}, \mathrm{Ni}, \mathrm{Cu}$, and Pd," Journal of Non-Crystalline Solids, vol. 352, no. 26-27, pp. 2772-2777, 2006.

[51] K. S. Jung, E. Y. Lee, and K. S. Lee, "Catalytic effects of metal oxide on hydrogen absorption of magnesium metal hydride," Journal of Alloys and Compounds, vol. 421, no. 1-2, pp. 179184, 2006.

[52] C.-S. Tsao, M.-S. Yu, C.-Y. Wang et al., "Nanostructure and hydrogen spillover of bridged metal-organic frameworks," Journal of the American Chemical Society, vol. 131, no. 4, pp. 1404-1406, 2009. 

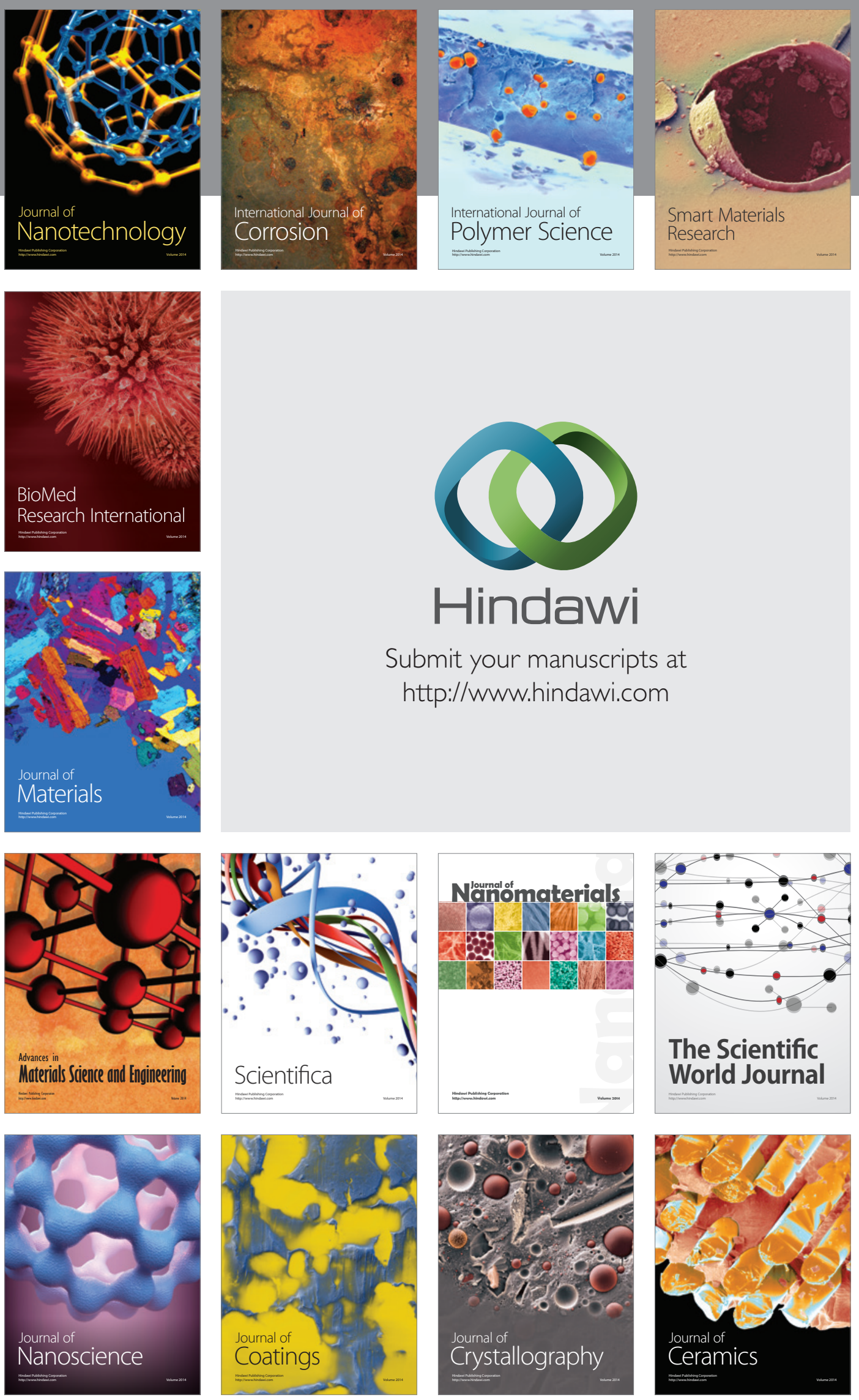

The Scientific World Journal

Submit your manuscripts at

http://www.hindawi.com

\section{World Journal}

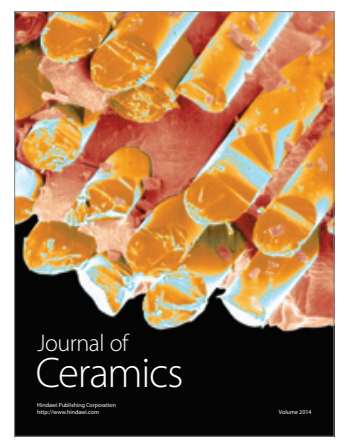

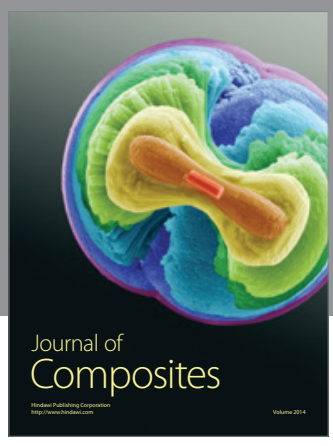
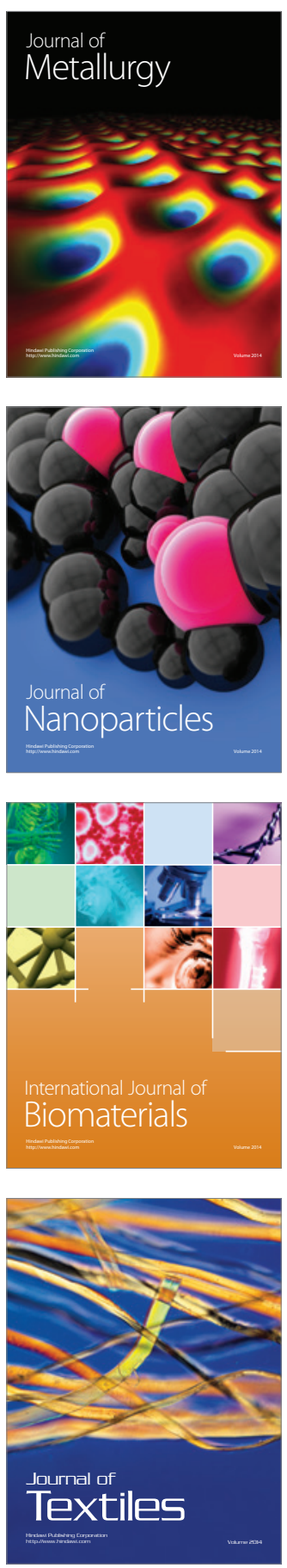